\title{
DESIGN CENTRADO NO DESIGNER: AUTORIA E AUTOIMAGEM NO TRABALHO DE STEFAN SAGMEISTER
}

\section{DESIGNER-CENTERED DESIGN: AUTHORSHIP AND SELF-IMAGE IN STEFAN SAGMEISTER'S WORK}

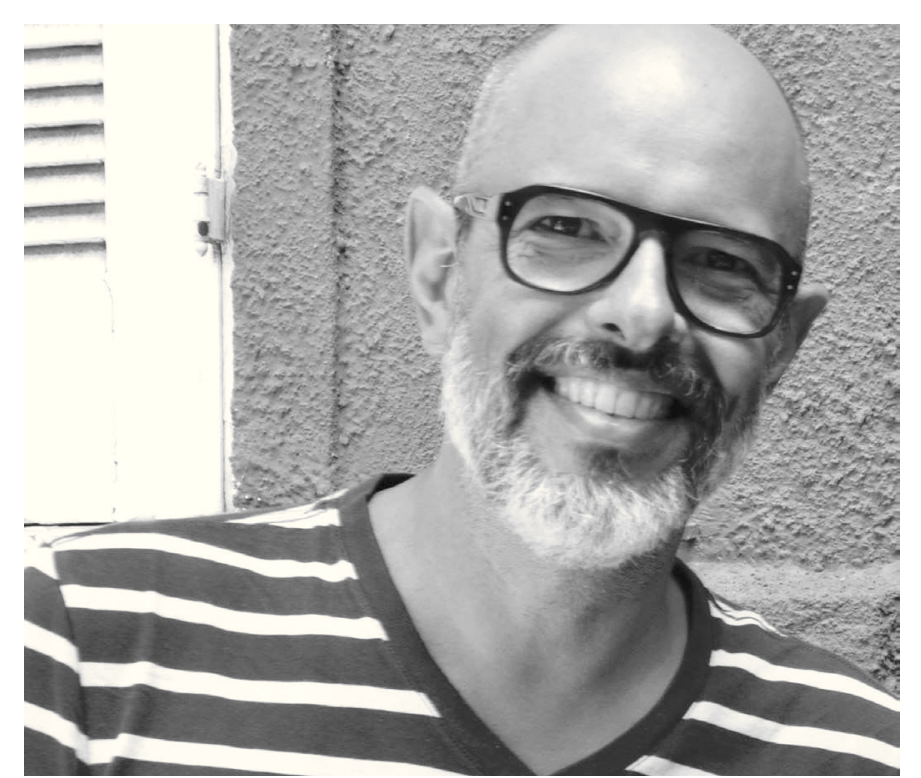

MARCOS ANDRE FRANCO MARTINS

Phd in Communications Science, Universidade Federal do Rio de Janeiro.

Escola Superior de Desenho Industrial /UERJ, Professor

marc.a.martins@gmail.com

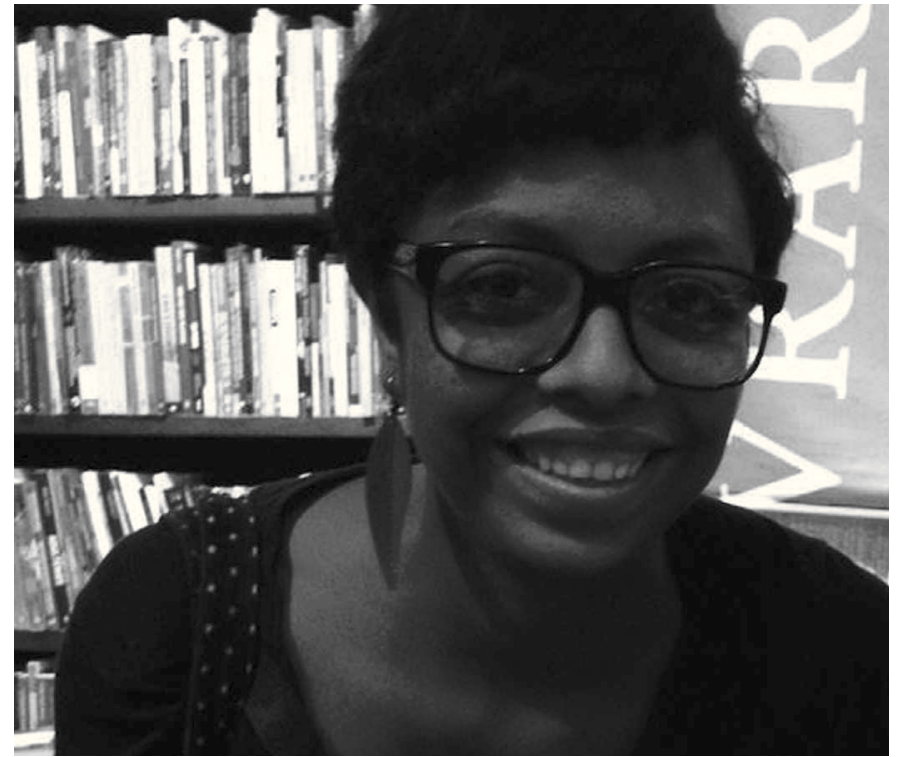

\section{CAMILA SOUZA RODRIGUES}

Mestranda em Design, Escola Superior de Desenho Industrial/ UERJ falecomkamy@gmail.com

\section{RESUMO}

O trabalho de Stefan Sagmeister se destaca pelo caráter experimental, autoindulgente e pelas características que visualmente identificam a sua autoria. Em grande parte de seus trabalhos - com destaque para os que têm como público-alvo os próprios designers - observa-se o uso da sua autoimagem como parte da composição e isso reforça a divulgação dentro 
da própria área. Nesta pesquisa pretende-se observar empiricamente de que maneira os indícios de autoria se revelam nos trabalhos do designer. A análise se dá através do levantamento do seu portifólio e da observação de elementos que, em conjunto, constituem o seu estilo, em especial, o uso do seu próprio corpo como recurso gráfico.

\section{PALAVRAS-CHAVE}

Autoria. Autoimagem. Stefan Sagmeister. Corpo.

\section{ABSTRACT}

Stefan Sagmeister's work stands out for its experimental and selfindulgent character and its characteristics that visually identify their authorship. In much of his work - especially on those whose target audience are the designers themselves - we observe the use of his self-image as part of the composition and how its strengthens publicity in his own area. This research is intended to empirically observe how the evidence of authorship are revealed in the designer's work by lifting his portfolio, observation of elements that together constitute his style and, in particular, the use of his own body as a graphic resource.

\section{KEYWORDS}

Autorship. Self-image. Stefan Sagmeister. Body.

\section{INTRODUÇÃO}

A palavra autoria, em seu sentido etimológico, derivado do latim auctor, referencia determinada obra à pessoa que a criou ou a promoveu, estabelecendo, assim, uma relação entre o sujeito (criador) e o objeto (criação).

A presença da autoria na área do design gráfico é questionada pela necessidade de se relacionar aspectos subjetivos à funcionalidade da comunicação. Porém, entende-se hoje, o designer como um mediador entre os objetos e seus usuários que não se isenta de imprimir seus valores, seus aspectos culturais e de formação, intencionalmente ou não, nos projetos que desenvolve. 
Klaus Krippendorff (2000) fala sobre a mudança de paradigma que ocorreu no design, onde a cultura científica, herdada do Renascimento, passou a dar lugar para o que ele denomina de "cultura projetual". Ao longo dessa trajetória a importância dos aspectos técnicos foi sendo substituída pelo "aumento gradual na consideração de aspectos humanos e sociais" ( $p$. 88). Como forma de diferenciar o foco nos aspectos técnicos dos aspectos humanos, Krippendorff afirma:

O foco no objeto valoriza critérios de projetos passíveis de serem generalizados e medidos sem o envolvimento humano. Esse tipo de foco é particularmente insensível à variedades culturais e individuais. (KRIPPENDORFF, 2000, p. 89).

O design, inicialmente centrado no produto deu lugar ao design centrado no usuário e posteriormente ao design centrado no ser humano, conforme proposto por Krippendorff (2000). Fazendo uma alusão à essas denominações, o título deste artigo sugere que os aspectos humanos que impactam os projetos vão além dos relacionados aos receptores das mensagens, passando também pelas características dos emissores através de seus próprios discursos e práticas. Krippendorff sugere que:

Para que o design sobreviva como uma profissão, ele deve aplicar seus princípios projetuais não apenas ao mundo material, mas também às suas próprias práticas, ao seu próprio discurso. Portanto, o design deve continuamente reprojetar o seu próprio discurso e ele próprio. (KRIPPENDORFF, 2000, p. 93)

Neste artigo, para discutir a questão do foco em particularidades do designer influenciando nas soluções gráficas propostas por ele, propõe-se localizar os aspectos de autoria no trabalho do austríaco radicado em Nova York, Stefan Sagmeister, pelo olhar das suas escolhas projetuais recorrentes e reconhecíveis. Em especial, analisaremos projetos em que ele usa a própria imagem - e na maioria dos casos a nudez - como recurso gráfico ou suporte para a transmissão de mensagens. A repetição de uma mesma tipologia cria uma consistência visual em seu trabalho quando analisado em conjunto.

Em um primeiro momento tomou-se o seu portifólio de trabalho 
para encontrar os pontos convergentes dentro das suas escolhas visuais. A partir daí, foram destacados os projetos em que o designer optou por usar a sua própria imagem e em seguida foi observado também de que forma a exploração da sua autoimagem se estendeu para além dos projetos e foi utilizada como recurso de divulgação do seu escritório, consequentemente, reforçando seu nome como uma marca, principalmente dentro do meio do design.

\section{DESIGN E AUTOIMAGEM}

Sagmeister não foi o primeiro designer a explorar a imagem do próprio corpo como recurso gráfico. A partir de meados dos anos 1960, a pasteurização do design ocidental começa a ser questionada por alguns designers suíços, como Wolfgang Weingart, que propôs trabalhos menos rígidos e mais intuitivos. O designer acreditava no envolvimento dos designers em seus projetos, como afirma Philip Meggs (2009):

Weingart defende o "enfoque Gutenberg" na comunicação gráfica: os designers, como os primeiros tipógrafos, devem envolver-se em todos os aspectos do processo (incluindo conceito, composição, produção, pré-impressão e impressão) para garantir a realização de seu ponto de vista. (MEGGS, 2000, p. 607-608).

Fortemente influenciada por Weingart, a designer norte-americana April Greiman trabalhava muito com experimentação nos processos gráficos. Considerada uma das pioneiras do design gráfico digital, Greiman explorou a sobreposição de imagens e texturas. Em 1987, a revista Design Quaterly solicitou a Greiman que projetasse uma de suas edições, onde o tema era a própria designer e seus trabalhos. O produto final foi uma revista/cartaz de 61 por 183 centímetros desenvolvida digitalmente por meio de captura de vídeo e sobreposições de imagens digitalizadas. 
Figura 1. "Does is make sense?" - Cartaz de April Greiman para a revista Design Quaterly.

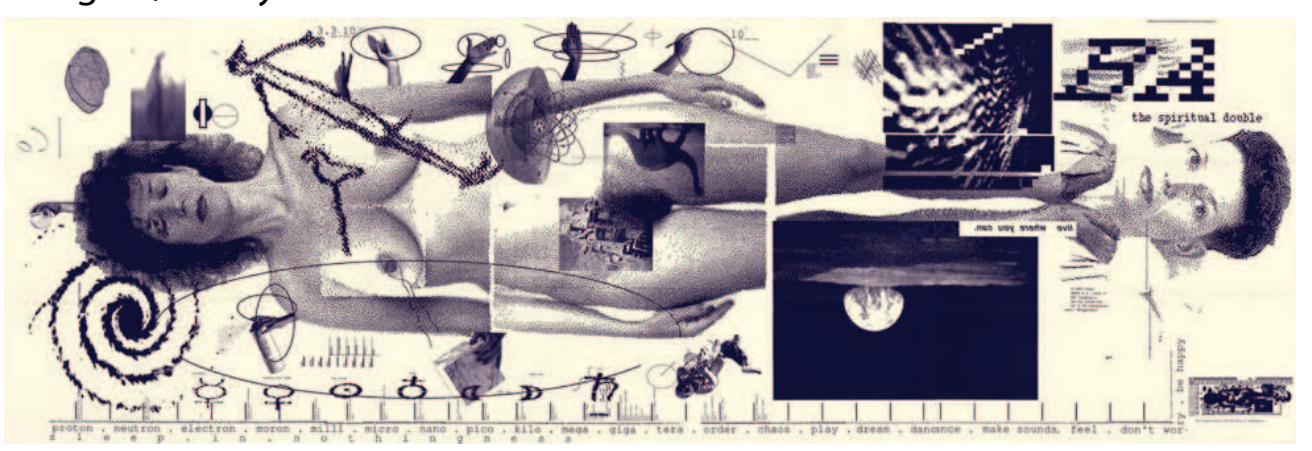

Fonte: Site Design is history

April Greiman alterou o padrão não só da forma de uma revista tradicional - que nesse caso foi toda integrada em um grande cartaz - como também na, então inovadora, forma de utilizar a imagem digital como recurso gráfico.

Greiman é uma importante predecessora do uso do autorretrato como estratégia expressiva no design e essa característica pode ser observada como referência para o trabalho de Stefan Sagmeister.

\section{A TRAJETÓRIA DE STEFAN SAGMEISTER}

Na inauguração do seu escritório, o Sagmeister Inc., em 1993, uma placa na parede exibia um de seus lemas profissionais - Estilo = Pum [1] - deixando clara sua crítica à supervalorização dos elementos estilísticos em projetos de design. Ele se orgulhava do seu escritorio não ter um estilo definido[2]. Apesar de achar, inicialmente, que o seu trabalho tinha como objetivo principal comunicação do conteúdo em detrimento da forma, Sagmeister observa que o estilo que se formou pelo conjunto das suas escolhas gráficas constantes era inegável e necessário para manter a consistência do seu trabalho.

Mesmo nos trabalhos do período em que Sagmeister acreditava não ter um estilo definido é possível, a partir de uma análise gráfica do seu portifólio, perceber alguns recursos gráficos constantes que representam indícios de autoria. Dentre esses recursos estão: experimentação manual, uso da imagem do corpo humano e de elementos da natureza e uso da imagem do seu próprio corpo. Para entender melhor como Sagmeister chegou a seu estilo quase artesanal de construção dos projetos, é importante conhecer 
brevemente sua trajetória.

De acordo com a hipótese de Pierre Bourdieu (1984), o capital cultural [3] de um indivídio é construído com base em suas experiências e vivências passadas através do seu contato com a família, com o ambiente educacional e com os meios sociais nos quais circula. A questão do gosto, e consequentemente das escolhas e do estilo de vida, não seria então uma propriedade inata a cada indivíduo e sim um resultado da combinação de condições às quais esse indivíduo foi exposto socialmente. Para Bourdieu, o gosto:

É a propensão e a capacidade de se apropriar (material e simbolicamente) de uma dada classe de objetos e práticas classificáveis e classificadoras na fórmula geral do estilo de vida, um conjunto unitário de preferências distintivas que transmitem a mesma intenção expressiva na lógica específica de cada um dos sub-espaços simbólicos, mobília, vestuário, língua, corpo. (BOURDIEU, 1984, p. 173).

A partir da teoria do gosto de Bourdieu podemos relacionar o consumo de referências e escolhas gráficas dos designers com os estímulos visuais e sociais a que eles foram expostos ao longo da vida através da sua conjuntura familiar, social, educacional e também por meio do espelhamento de modelos da própria área.

Em sua família, Sagmeister teve suas primeiras referências profissionais. Com pais empreendedores e avô tipógrafo, cresceu cercado por tipos e tintas, o que acabou influenciando seu foco no fazer artesanal. Cursou a Universidade de Artes Aplicadas de Viena, e terminou seus estudos já em Nova York, no Pratt Institute, onde conseguiu uma bolsa de estudos. Como explana em seu livro Made You Look (2001) esse período foi muito rico em experiências visuais: "A vida em Nova York é marcada por grandes contrastes (...) e ele mergulhou naquele estilo de vida como um nativo". (p. 47, tradução nossa).

Sua próxima experiência profissional foi montar a área de design da agência Leo Burnett em sua filial em Hong Kong onde ficou por poucos anos. Sagmeister decidiu voltar a Nova York para trabalhar com seu grande ídolo no design, Tibor Kalman, no escritório M\&Co. Após seis meses de trabalho, Kalman decide se dedicar somente ao seu trabalho de editor da revista Colors 
e encerra as atividades do M\&Co. A partir daí Sagmeister, tendo trabalhado para o escritório que mais admirava, resolveu que o único caminho possivel era abrir o seu próprio, o Sagmeister Inc.

Apesar do pouco tempo de trabalho juntos, Kalman aconselhou Sagmeister sobre o que considerava essencial para manter um escritório de design de sucesso: se esforçar para continuar pequeno, se divertir trabalhando e aproveitar toda oportunidade de fazer seu trabalho aparecer na mídia. Notadamente esses conselhos nortearam a forma de conduzir o Sagmeister Inc.

\section{AUTOIMAGEM}

A primeira peça desenvolvida por Sagmeister Inc. coincide com o primeiro momento em que o designer explora seu corpo, nu, como recurso gráfico. Ele desenvolveu cartões postais que foram enviados para potenciais clientes e amigos como convite para sua festa de lançamento, em janeiro de 1994. Em sua imagem e no texto de apoio, Sagmeister sugere que é preciso ter coragem para abrir seu próprio escritório (Figura 2).

Figura 2. "Convite postal de abertura, Sagmeister Inc.".
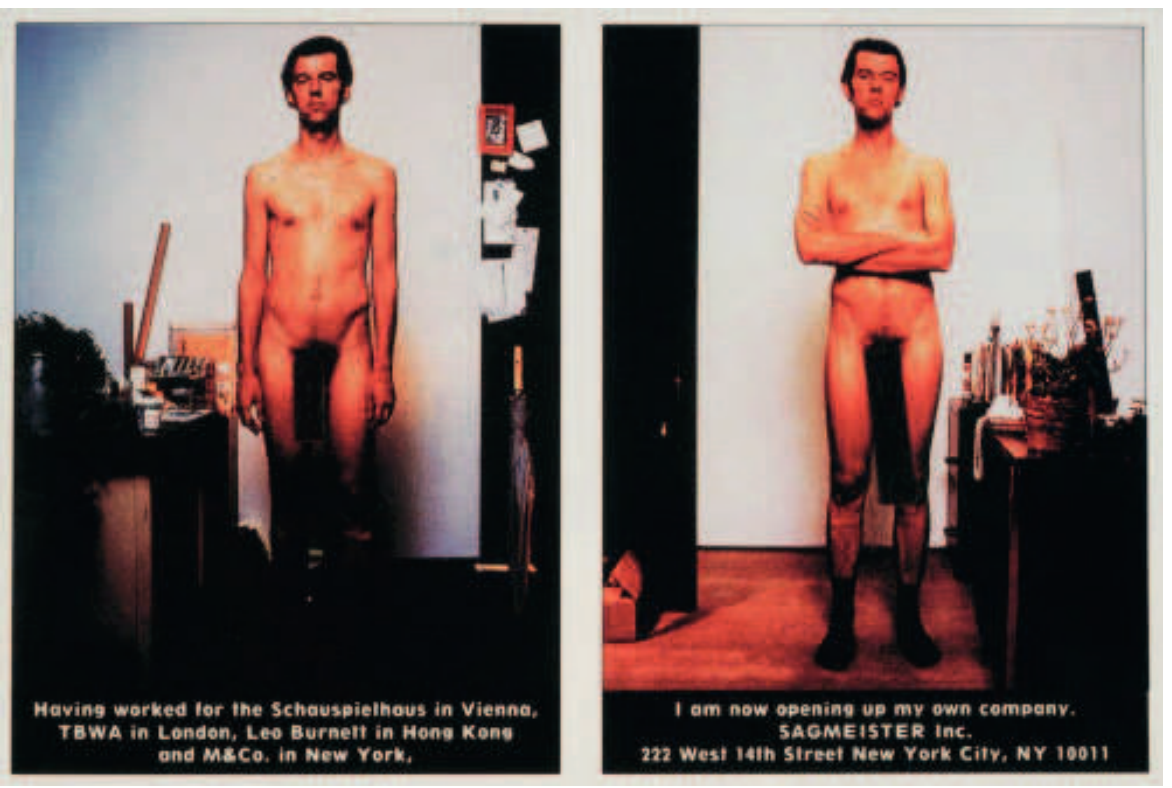

Fonte: SAGMEISTER, 2001, p. 115. "Tendo trabalhado para a Schauspielhaus em Vienna, TBWA em Londres, Leo Burnett em Hong Kong e M\&Co. em Nova York (...) Eu agora estou abrindo meu próprio escritório. Sagmeister Inc." (tradução nossa). 
Sagmeister utiliza a própria imagem para gerar um choque inicial no observador e para reforçar a ousadia e criatividade a que se propunha. O designer se coloca como elemento central, dentro do seu escritório, enfatizando seu papel de "gênio criador" em lugar de mostrar os trabalhos desenvolvidos até então. Nesse momento, Sagmeister marca o início da estratégia de foco na autoimagem.

No livro Whereishere (1998), compilado pelo designer Lewis Blackwell com o objetivo de expor o trabalho de diferentes designers contemporâneos, Sagmeister, em uma das páginas duplas, optou pela produção de uma composição onde o nome do livro aparece arranhado no seu próprio corpo. Além de expor sua imagem, o designer transmitiu a mensagem utilizando o corpo como suporte iniciando uma atitude que pode ser comparada, em parte, à uma performance artística.

Com relação a esse trabalho, Rick Poynor escreveu uma crítica na revista Graphis sobre a obsessão pela própria imagem característica da época. Ele acreditava que essa obsessão estava sendo reforçada pela "veia autoindulgente do design gráfico contemporâneo". Em resposta a essa afirmação, Sagmeister utiliza o argumento de que o livro tinha como públicoalvo os designers e por isso requeria trabalhos pessoais e envolvimento. "Se você está fazendo trabalhos para outros designers, é melhor que você fale sobre design ou sobre você mesmo" [4].

Ainda em 1998, desenvolvendo proposta para capa de uma edição especial sobre Nova York da revista japonesa IDEA, sugeriu um autorretrato seu ao lado de seu funcionário Hjalti Karlsson com um jogo de "ligue os pontos" sobre seus rostos. A ideia foi aceita e o objetivo era enfatizar as diferenças culturais entre os países, mostrando que na cabeça dos nova iorquinos, representados pelos designers, só passam dois pensamentos: dinheiro e mulheres. (Figura 3). A capa desenvolvida poderia transmitir o mesmo conceito proposto se no lugar do próprio designer fosse utilizado um modelo fotográfico, até mesmo desconhecido. Porém, o designer teve como estratégia reforçar a associação do próprio rosto ao ideal cosmopolita nova iorquino, mantendo o conceito de jocosidade e irreverência no trato com sua autoimagem. 
Figura 3. "Capa da Revista Idea Design e a mesma peça com a intervenção sobre ela".
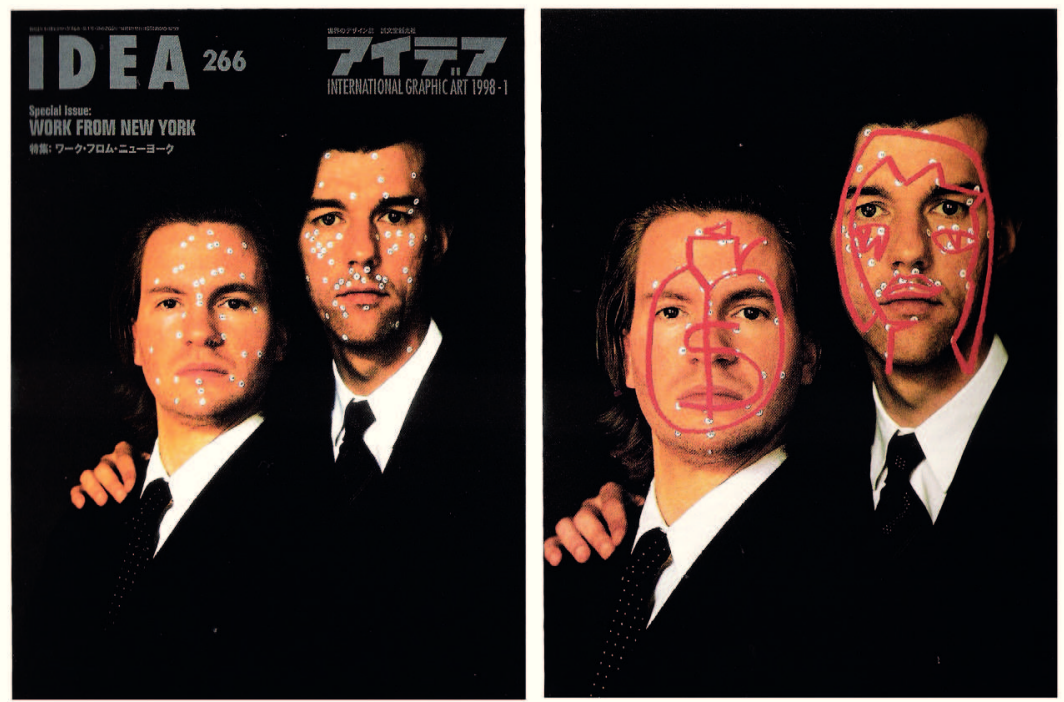

Fonte: SAGMEISTER, 2001, p. 184-185.

Depois de experimentar escrever um pequeno texto na pele no projeto Whereishere, Sagmeister resolveu repetir a estratégia, em 1999, em trabalho voluntário para AIGA. O cartaz desenvolvido teve o texto todo escrito no seu corpo com uma lâmina. (Figura 4). Apesar da dor e da vontade de desistir no meio do processo, como descreve em seu livro Made You Look (p.191), o designer alega que o cartaz cumpriu com sucesso o seu objetivo. $O$ evento teve audiência maior do que a esperada e trouxe mídia espontânea para o escritório e, consequentemente para o designer. Para Sagmeister, em sua afirmação pouco modesta, o cartaz não só trouxe mudanças para o seu escritório como trouxe também mudanças nas aspirações dos novos designers: "O cartaz (...) representou um ponto de mudança na profissão de design, longe da aspiração pela perfeição digital em direção a uma maior valorização da marca pessoal de um designer" [5]. Com esta peça Sagmeister expressou sua intenção de se colocar na posição de designer performático assumindo o interesse de estar no patamar equivalente às mensagens a serem transmitidas em suas peças. 
Figura 4. "Cartaz para a palestra Cranbrook academy of art and aiga detroit".
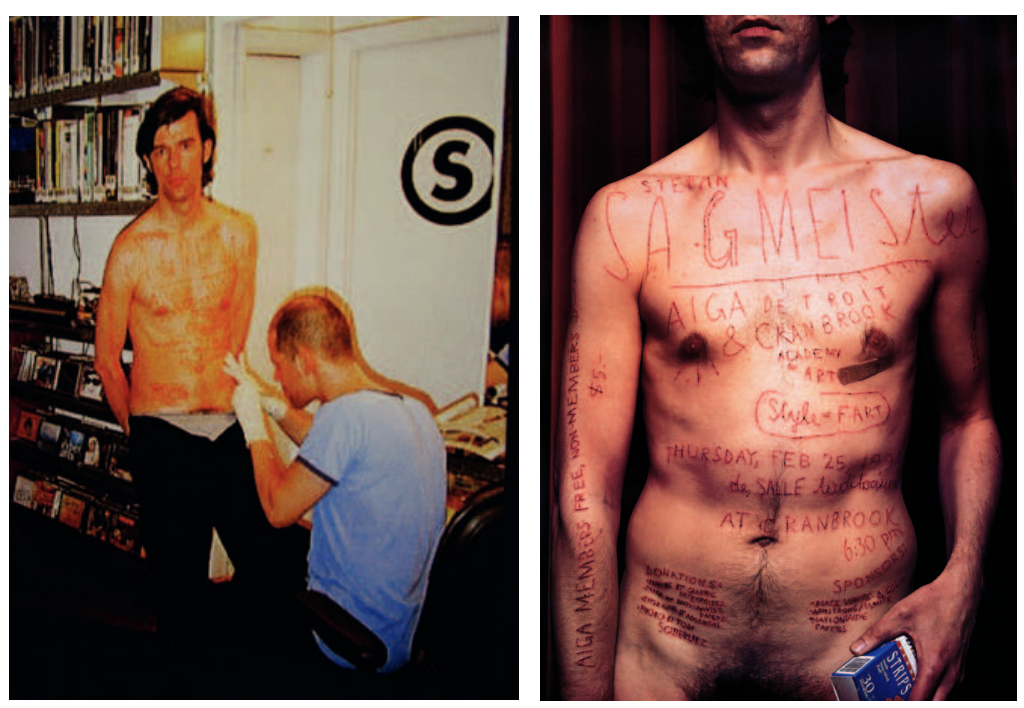

Fonte: SAGMEISTER, 2001, p. 190.

Depois da repercussão do cartaz, em 2002, o designer foi convidado para a sua primeira exposição individual no museu MAK em Vienna, sua cidade natal. O cartaz da exposição, desenvolvido por seu escritório apresentava o seu corpo nu, dessa vez com vista posterior e mostrava parte do já famoso cartaz desenvolvido para a AIGA (Figura 5). Assim como o primeiro cartaz, esse projeto também explora a tipografia manual que acabou se tornando outro ponto recorrente nos trabalhos do designer. A abertura da exposição contou com mais público do que o esperado com resultado positivo.

A partir de então, o recurso de usar sua própria imagem em peças de divulgação de eventos voltados para designers foi usado recorrentemente. No ano seguinte, 2003, outro cartaz foi desenvolvido para uma exposição em Zurich com um retrato de Sagmeister e do designer Matthias Ernstberger (Figura 6). Os ternos representavam gráficos do número de vezes que cada peça desenvolvida por eles apareceu em revistas de design e catálogos. Quanto maior o número de aparições, maior o tamanho da peça em relação às outras. Esse tipo de trabalho passou a ir além do aspecto informativo com o conteúdo do evento e passou a ser também uma forma de divulgar sua imagem e os trabalhos do escritório perante a comunidade de design. 
Figura 5 e 6. " Cartazes para exposição em Vienna e em Zurich".
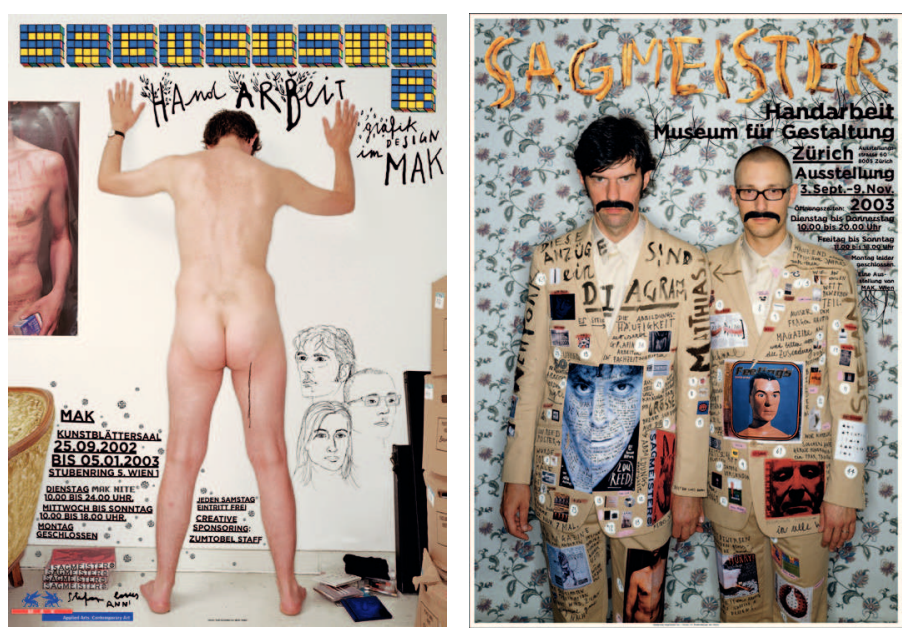

Fonte: Website Sagmeister \& Walsh.

Ainda em 2003, Sagmeister preparou o que se assemelha a uma performance para desenvolver o cartaz para uma exposição de design em Tokyo. Na parte superior do cartaz, o designer aparece sentado no sofá com o seu peso padrão. Na parte inferior do cartaz, o designer aparece rodeado por dezenas de embalagens de alimentos que ele afirma ter ingerido e com visíveis quilos a mais (Figura 7). A peça transmite a ideia da participação ativa do designer em todo o processo de desenvolvimento, o que representa, conceitualmente, a importância crucial da figura de Sagmeister para que os argumentos retóricos inerentes ao trabalho sejam efetivados.

Na descrição do cartaz de exposição para a School of Visual Arts (Figura 8) em seu site, em 2004, Sagmeister assume a recorrência de suas escolhas visuais quando declara que tinha prometido não usar mais tipografia feita à mão e que não apareceria mais em seus cartazes. Mas depois de algumas tentativas, afirmou que novamente essa foi a melhor opção [6]. 
Figura 7 e 8. "Cartaz Sagmeister on a binge" e "Cartaz para SVA Exhibition".
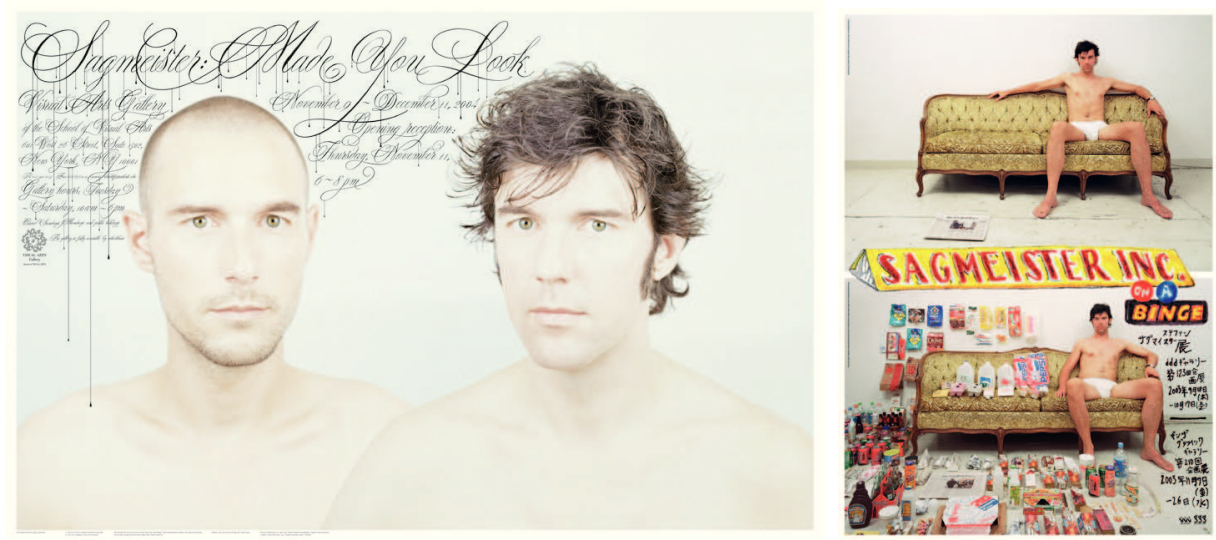

Fonte: Website Sagmeister \& Walsh.

Na volta do seu ano sabático, em 2008, o designer lançou seu segundo livro chamado Things I have learned in my life so far (Coisas que aprendi na minha vida até agora) onde expõe anotações do seu diário. O livro possui quinze opções de capa que podem ser trocadas e aparecem em sobreposição à imagem do seu rosto. (Figura 9). Nesse momento o designer se coloca como porta-voz de conhecimentos para outros designers associando a autoimagem à de alguém (pouco modesto) que tem algo a dizer sobre o que aprendeu.

Em 2012, Sagmeister mobilizou todos os funcionários do seu escritório a participarem ativamente do cartaz promocional para Les Arts Décoratifs de Paris. Todos tiveram suas cabeças raspadas e a tipografia do cartaz foi escrita com os próprios cabelos (Figura 10). Além da tipografia experimental, recurso recorrente, a partir desse momento a participação na forma de performance fica mais ativa e se estende a todos os funcionários. 
Figura 9 e 10. "Livro Things I have learned in my life so far" e "Cartaz promocional para Les Arts Decoratifs".
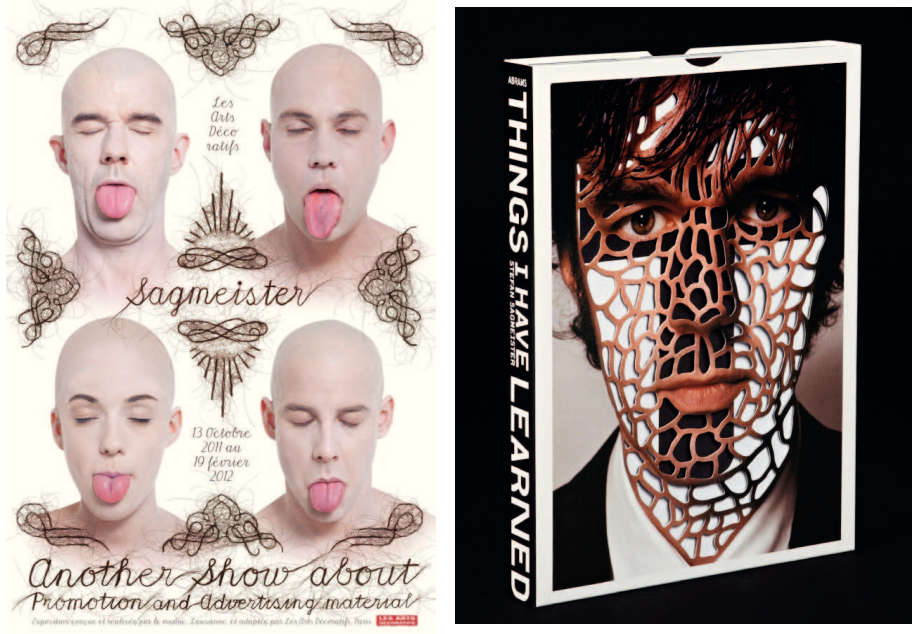

Fonte: Website Sagmeister \& Walsh.

Dezenove anos após o lançamento do Sagmeister Inc., o designer anuncia sociedade com sua até então jovem assistente Jessica Walsh. Para divulgar sua parceria, Sagmeister faz uma releitura do primeiro postal que enviou para clientes em que aparecia nu. Agora Walsh aparece ao seu lado, sobre uma pilha de livros, também nua no e-mail marketing enviado. (Figura 11). Com a nova sócia, Sagmeister pretende se dedicar mais aos projetos autorais, enquanto Jessica Walsh coordena os projetos comerciais. A peça em questão marca uma nova fase de trabalho, mas, ao fazer a releitura, Sagmeister reforça a ideia de que os sócios devem ocupar o papel principal no escritório e na estratégia de posicionamento da empresa. 
Figura 11. "E-mail marketing de anúncio da entrada da nova sócia do escritório, Jessica Walsh".

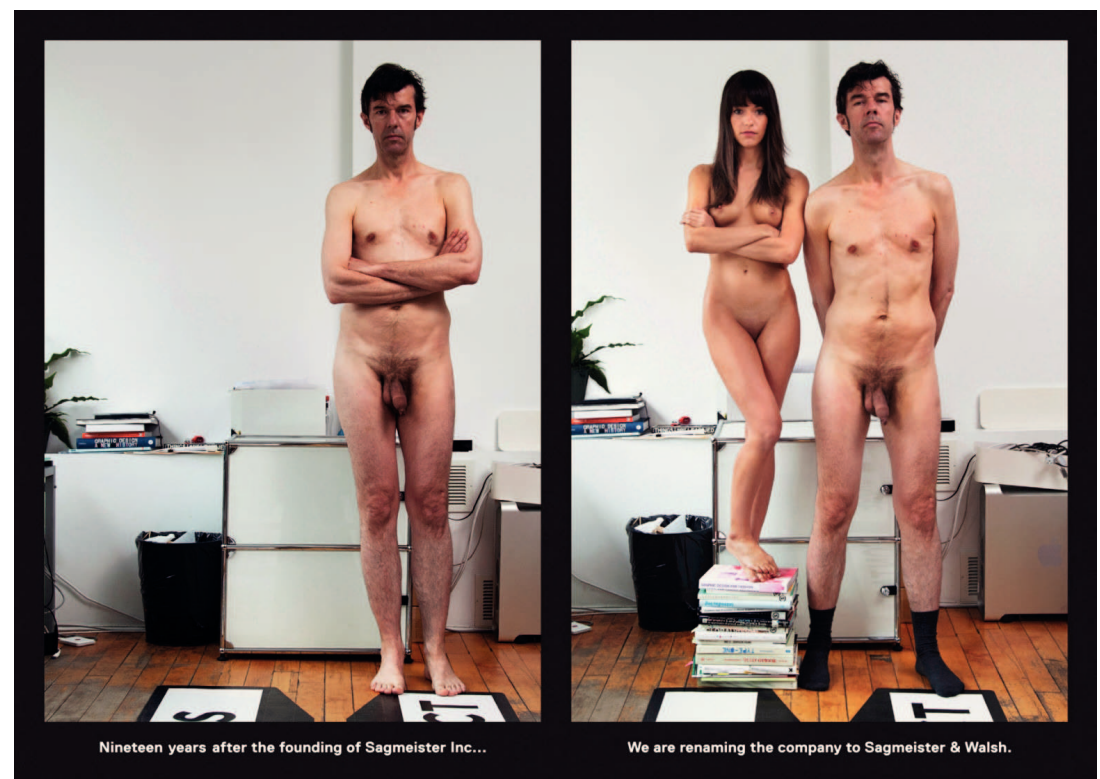

Fonte: Website Sagmeister \& Walsh. “Dezenove anos depois de fundar o Sagmeister Inc. (...) Nós estamos renomeando a empresa para Sagmeister \& Walsh" (tradução nossa).

Mesmo com a entrada de Walsh o escritório continuou com a estratégia de utilizar a imagem dos sócios e dos seus funcionários, sempre com apelo ao corpo. Em 2013, cartazes promocionais desenvolvidos para a School of Visual Arts exibiam o texto "Take it on" sobre o rosto de Stefan, Jessica e do estagiário do escritório, escrito com diferentes suportes experimentais (Figura 12).

Figura 12. "Cartaz Take ir on para a SVA NYC".

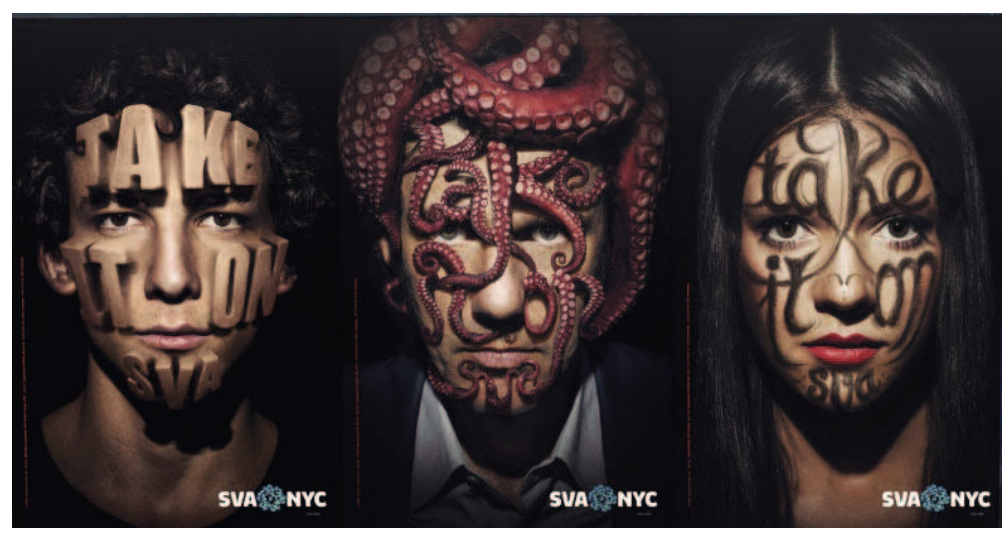

Fonte: Website Sagmeister \& Walsh. 
Em 2014 a Adobe contratou o escritório para desenvolver algumas reinterpretações visuais da sua marca. A proposta apresentada envolveu a participação direta dos sócios com a simulação de um talk show onde os dois disputavam quem fazia a melhor releitura do logotipo da Adobe com diversos materiais inusitados (Figura 13). A ação foi desenvolvida em cinco episódios em vídeo disponibilizados nas redes sociais [7]. A autoimagem, então, deixou de ser apenas estática, para ser explorada também de forma dinâmica, tangibilizando a atitude performática do designer.

Figura 13. "Logotipo da Adobe e suas releituras propostas por Sagmeister \& Walsh".

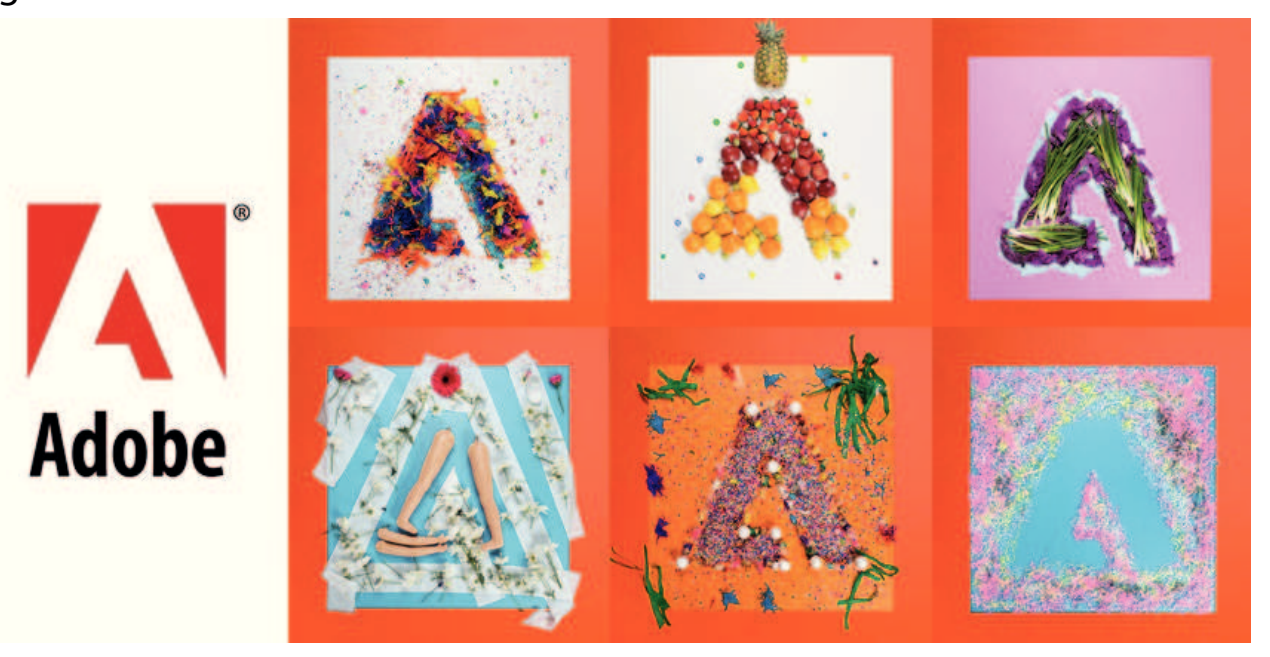

Adaptado de: Website Sagmeister \& Walsh.

Além da autoimagem nas peças gráficas, Sagmeister também utiliza o recurso da personificação do seu escritório em outras formas de apresentação da empresa. O website institucional apresenta em sua página inicial um vídeo que mostra a sala principal do escritório em tempo real, durante 24 horas. Os botões do menu da página existem fisicamente, colados em adesivo no chão da sala onde os designers trabalham todos os dias. O site também é voltado para o acesso da mídia. É possível fazer o download de fotos dos sócios, de todos os projetos expostos na página em alta definição além de textos na forma de release preparados para a imprensa. Recentemente, para divulgar o lançamento de melhorias no website os funcionários, e os sócios, participaram de uma sessão de fotos simulando um ambiente sem 
gravidade. E como não podia deixar de ser, todos estavam nus.

\section{CONCLUSÃO}

Após analisar as peças gráficas onde Stefan Sagmeister utiliza sua imagem como recurso gráfico observam-se alguns pontos de convergência. Além da combinação constante deste recurso com outros elementos constitutivos do seu estilo, nota-se que essas peças, são, em sua maioria, voltadas para um público-alvo dentro do próprio meio do design ou onde circulam potenciais clientes.

Pode-se concluir que existe um reforço no seu posicionamento, uma vez que a autoimagem contribui para a construção de sentido das mensagens a serem transmitidas com mais força dentre os designers, onde ele é uma figura reconhecível.

Sagmeister utiliza o discurso do desejo de tocar o coração das pessoas através do design. Sua relação com o corpo e o seu envolvimento presencial nas peças é notável. De certa forma, intervir, real ou virtualmente no próprio corpo usado como suporte é a sua forma de utilizar o design para interferir no mundo.

\section{NOTAS}

[1] Style $=$ Fart, no original

[2] "Durante muito tempo nos orgulhamos de não ter um estilo, o que se tornou impossível de defender. Isso porque, se você realmente mudar sua abordagem estilística a cada projeto, é impossível chegar a um novo em uma semana ou um mês sem copiar tanto estilos históricos ou estilo de um determinado designer. Embora não cubra todo o nosso trabalho, eu diria que estamos provavelmente mais conhecidos por nossa característica artesanal." (SAGMEISTER, 2006, tradução nossa).

[3] O conceito de capital cultural proposto por Pierre Bourdieu diz respeito à uma predisposição ou tendência de cada indivíduo a gostar de determinados produtos da cultura influenciados por saberes, conhecimentos e experiências acumuladas ao longo da vida. [4] "If you're doing work for other designers you'd better talk about either design or yourself." (SAGMEISTER, 2001, p. 178-179, no original).

[5] "The poster (...) signalled a turning point for the design profession, away from aspirations of digital perfection toward a higher appreciation for a 
designer's personal mark." (SAGMEISTER, 2001, p. 191, no original). [6] Há alguns meses eu prometi: 1. Eu não vou usar nossa tipografia manual como assinatura. 2. Eu não vou mais aparecer em nenhum de nossos cartazes. Nós vamos realmente experimentar inúmeras outras ideias, tudo refrescantemente livre de rabiscos feitos a mão e vaidosos autorretratos.No final, nós gostamos mais de nós mesmos novamente. Desculpe. Vamos continuar tentando. (Fonte: Site Sagmeister \& Walsh, tradução nossa).

[7] Os vídeos podem ser acessados na plataforma Vimeo. Disponível em: <https://vimeo.com/87875328>. Acesso em: 10 abr. 2014.

\section{REFERÊNCIAS}

BOURDIEU, Pierre. A distinção: crítica social do julgamento. Tradução: Daniela Kern;Guilherme J. F. Teixeira. São Paulo: Edusp; Porto Alegre, RS: Zouk, 2007.

DESIGNBOOM. Stefan Sagmeister Interview. 2006. Disponível em: $<$ http://www. designboom.com/interviews/designboom-interview-stefan-sagmeister-2/>. Acesso em: 25 mar. 2014.

FLASK, Dominic. April Greiman. Design History. Disponível em: $<$ http://www. designishistory.com/1980/april-greiman/>. Acesso em: 01 abr. 2014.

KRIPPENDORFF, Klaus. Design centrado no ser humano: uma necessidade cultural. Tradução: Gabriela Meirelles. Revisão técnica de tradução: Lucy Niemeyer. Estudos em Design, Rio de Janeiro, v. 8, n. 3, p. 87-98, set. 2000.

MEGGS, Philip. História do design gráfico. $4^{\text {a }}$ edição. São Paulo: Cosac Naify, 2009.

SAGMEISTER, Stefan. Made You Look. Texto por Peter Hall. New York: BoothClibborn Editions, 2001.

SAGMEISTER, Stefan; WALSH, Jessica. Website Sagmeister \& Walsh. Disponível em: <http://www.sagmeisterwalsh.com/>. Acesso em: 05 abr. 2014.

Dr. Marcos Martins integra, desde 2010, o corpo docente da Esdi (Escola Superior de Desenho Industrial), onde é atualmente Chefe do Departamento de Programação Visual. Como professor, seus principais campos de pesquisa são design de interação e de experiência do usuário, estudos midiáticos e interseções entre Arte e Design. De 1984 a 1989, trabalhou, como curador e designer de exposição, em instituições culturais como Museu Nacional de Belas Artes, Paço Imperial e Funarte. 
Recebido em: 09/09/2014; Aceito em: 07/11/2014.

Esta obra foi licenciada com uma Licença Creative Commons.
Neste campo, recebeu uma bolsa CAPES/Fullbright para um período de quatro meses (1987-1988) de pesquisa no Boston Museum of Fine Arts, em Boston, Estados Unidos. Em 1992, apoiado por uma bolsa CNPq, concluiu o mestrado em Computer Art na School of Visual Arts, em Nova York, Estados Unidos. No mesmo ano, sua animação em computação 3D chamada "Falling Apart" foi selecionada e exibida na conferência SGGRAPH 1992, em Chicago, Estados Unidos. Durante sua estada nos EUA, trabalhou na IBM (T. J. Watson Research Center) fazendo modelagem 3D para a animação "Humming Bird", também exibida na SIGGRAPH'92. Entre 1993 e 2009, criou diversas peças de design gráfico e de interação, com ênfase nas áreas de design de interface e design editorial para exposições de arte. Mais recentemente, publicou artigos sobre design de interação, estudos midiáticos, e fotografia, e co-editou o livro "Dispositivo Fotografia e Contemporaneidade". Em 2014, apresentou o artigo "Prototyping in a Learning Environment" na 16th International Conference on HumanComputer Interaction. Na Microsoft Design Expo 2014 (Seattle, EUA), ele recebeu o prêmio Best Overall Design por sua participação como orientador do projeto de design de interação "Platform".

Camila Rodrigues é designer do Rio de Janeiro, Brasil. Tem graduação em Design Gráfico e em Comunicação Social, ambas pela Escola Superior de Propaganda e Marketing do Rio de Janeiro (ESPM-Rio). Atualmente, é mestranda no programa de pós-graduação em Design ESDI/UERJ, pesquisando sobre autoria no design e identidade dos designers. Trabalha como empreendedora há cinco anos e é sócia do estúdio LabLab Design há três, trabalhando em projetos gráficos e editoriais. 